\title{
Do Hedge Funds Arbitrage on Asset Growth, Earnings Momentum and Equity Financing Anomalies?
}

\author{
Daniel T. Lawson ${ }^{1} \&$ Robert L. Schwartz ${ }^{1}$ \\ ${ }^{1}$ Department of Finance \& Legal Studies, Indiana University of Pennsylvania, Indiana, USA \\ Correspondence: Daniel T. Lawson, Department of Finance \& Legal Studies, Indiana University of Pennsylvania, \\ Indiana, PA 15705, USA. Tel: 1-724-357-5767. E-mail: dlawson@iup.edu
}

Received: July 8, 2018

doi:10.5539/ijef.v10n9p38
Accepted: July 24, 2018

Online Published: August 10, 2018

URL: https://doi.org/10.5539/ijef.v10n9p38

\begin{abstract}
This paper analyzes the risk-adjusted performance of hedge funds and their overall ability to arbitrage on known market anomalies. This is done by testing three anomaly factors capturing total asset growth, equity financing, and earnings momentum in addition to the traditional Fama and French (1993) and Carhart (1997) four-factor model and Fung and Hsieh (2001) risk factors. Our results suggest that the average hedge fund employs a strategy consistent with the total asset growth and earnings momentum anomalies but contradictory to the equity financing anomaly of Hirshleifer and Jiang (2007). Multi-factor alpha generation does seem to persist over longer periods of time which suggests the use of other untested, return-generating arbitrage methods.
\end{abstract}

Keywords: hedge funds, arbitrage, market anomalies, behavioral finance, efficient markets

\section{Introduction}

\subsection{Factor-Investing and Risk Arbitrage}

Hedge funds are reputed for being top-tier investment vehicles for accredited investors with greater risk appetites and strong desire for excess returns. Hedge fund managers must have superior resources and strategies in order to provide for these abnormal returns; hence, they should be well-positioned and aware of pricing anomalies. Of course, this is based on the assumption that market anomalies do in fact exist, a notion that has been heavily vetted by academics in the finance discipline. See, for example Keim and Ziemba (2000) and Fama and French (2007). Moreover, most hedge funds are not required to report trading patterns or investment holdings, and this veil of confidentiality, along with a lack of asset class and investment strategy restrictions, is what theoretically provides hedge funds with the unique opportunity to arbitrage on market anomalies.

\subsection{Are Hedge Funds Worth Their Salt?}

Given the notion that hedge funds should be properly equipped to produce abnormal returns, if tested, they should load positively on known anomaly factors. That is, if we were to regress hedge fund returns on the well-documented Fama and French (1993) and Carhart (1997) risk proxies and multiple other anomaly factors measuring asset growth, equity financing, earnings momentum, and trend-following behavior, we should find significant correlation. Further, if managers are leveraging known anomalies, their activity should be self-destructing as they drive asset prices to their true levels and inefficiencies dissipate. Unless of course, the lack of transparency into hedge fund activity counteracts this affect. We pursue this arbitrage hypothesis within the context of the paper while also testing whether hedge funds produce alpha, or unexplained excess return.

\section{Literature Review}

\subsection{Market Efficiency}

The theory of market efficiency is a framework that can be traced back to the works of prominent mathematicians such as Louis Bachelier in his 1900 dissertation asserting the notion that capital markets are price efficient, albeit in the context of financial options. Fast forward fifty years to an era of computer-aided empirical testing and scholars such as Markowitz (1952), Kendall (1953) and others lay the groundwork for modern portfolio theory. Since the 1960s, academics have rallied producing countless papers in support and opposition to the efficient markets hypothesis and ability to generate alpha. In their hunger for a single risk-adjustment framework, finance experts have propelled multi-factor modeling into the forefront of the 
investments literature.

\subsection{Market Anomalies}

Per Treynor (1961 and 1962), Sharpe (1964), Lintner (1965a,b), and Mossin (1966), the capital asset pricing model offers an empirical approximation of economic reality in capital markets. The general premise is that all stocks have a true price (or value) which is a function of the amount of risk the asset bears. If the stock carries risk which is at a premium (in excess) of a diversified market portfolio, then investors will require compensation for that additional risk. This is reflected through an increase in the assets trading price and therefore the total return to the investor.

Ball and Brown (1968) found two exceptions (anomalies) to this risk-return tradeoff seen in an "efficient market." Their research observed abnormal stock returns following positive earnings announcements and decline in stock returns following negative announcements. The ability to generate abnormal returns by utilizing a long-short strategy applied to post-earnings-announcement drift was later confirmed by Foster, Olsen, and Shevlin (1984), Bernard and Thomas (1989), Hew, Skerratt, Strong, and Walker (1996), and Booth, Kallunki, and Martikainen (1996). This brought to surface a new returns anomaly dubbed, "Post-Earnings Announcement Drift" which is captured in our multi-factor model.

Two and a half decades later, Eugene Fama and Kenneth French found what seemed to be two additional anomalies to the risk-return framework. Fama and French (1993) found that small-cap and value stocks tend to outperform the market. Originally it was proposed that these were violations to the praised risk-return paradigm, such that investors were earning "risk-less return." In strong disagreement, the two scholars argued that these relationships should instead reflect additional "risk premiums" that investors are appropriately rewarded for. The rationale stated that small-cap and value stocks are riskier and should certainly yield higher returns to compensate investors. This is a generally accepted view of the Fama-French factors in current literature and we extend them to our hedge fund sample.

Shortly following the 1993 paper on market efficiency and risk premiums, Mark Carhart published a study outlining what was found to be a returns anomaly associated with momentum. Carhart (1997) found that going long assets with high prior returns and shorting assets which had previously generated low returns would in fact offer investors additional yield without increased risk. This is a stark jab against the efficient market hypothesis which states that no arbitrage opportunities, aka the ability to generate risk-less return, should be possible. We include the Carhart (1997) factor in our model due to its cited explanatory power.

\subsection{Additional Anomaly Factors}

Over recent decades, a number of prominent scholars have brought to light further market anomalies which seem to contradict efficient markets. Most of these have been revised or discredited through continued empirical analysis (see Brav, Geczy, \& Gompers, 2000; Eckbo, Masulis, \& Norli, 2000; Boehme \& Sorescu, 2002; and Fama \& French, 2007), or have been arbitraged away after exploitation had ensued (see Marquering, Nisser, \& Valla, 2006).

Fung and Hsieh (1997), Brown, Goetzman, and Park (1997), and Brown, Goetzman, and Ibbotson (1999) published much of the original investigation into hedge fund performance identifying many of the now common strategies and fund characteristics. Fung and Hsieh (1997) studied hedge fund performance and detected very little relationship between fund and index performance over time. Fung and Hsieh (1997, 2001), Mitchell and Pulvino (2001), and Agarwal and Naik (2004) also noted a non-linear risk and return relationship within their samples.

Hirshleifer and Jiang (2007) find success in going long a portfolio of repurchase firms and short a portfolio of new issue firms. This anomaly has also been documented by Loughran and Ritter (1995, 2000), Lakonishok and Vermaelen (1990), Ikenberry, Lakonishok, Vermaelen (1995), and Daniel and Titman (2006). According to Cooper, Gulen, and Schill (2007), an asset growth anomaly may also exist such that a strong negative correlation is present between a firm's asset growth rate and subsequent abnormal returns. Fama and French (2007) produce a refined study where this only applied to mean returns on microcap and small-cap stocks. Both an asset growth factor and equity financing factor are included in our analysis.

Given existing research, it is certainly possible that hedge funds which advertise the use of factor-based strategies are indeed profiting from market inefficiencies. Under the shelter of minimal public disclosure requirements, hedge fund managers may be able to generate abnormal returns over extended periods with little, if any, dilution of effect. Moreover, given the capital requirements for hedge funds, most arbitrageurs ought to be in an adequate financial position to execute potentially costly strategies. We investigate long-term hedge fund 
performance and historical factor utilization over a cross-section of strategies by analyzing loadings on prominent anomaly factors.

\section{Data and Methodology}

\subsection{Baseline Data}

Our data consists of 3,665 individual hedge funds (1,430 active funds and 2,235 defunct funds) from Barclay Hedge Fund DataFeeder and Barclay Graveyard Database that are reported in U.S. currency, net of all fees, and have at least 24 consecutive months of performance data between January 1, 1994 and December 31, 2008. Reported strategies contain a minimum of 10 individual hedge funds. Fama and French (1993) and Carhart (1997) factors are sourced from Kenneth French's website and Fung and Hsieh (2001) factors from David Hsieh's website. Data used to construct the additional anomaly factors were obtained from Bloomberg.

\subsection{Survivorship and Incubation Bias}

Due to the voluntary nature of a hedge fund's information sharing practices, certain biases must be controlled for when interpreting returns data. Survivorship bias is a prominent example in which returns from hedge funds which have been liquidated or are non-reporting are omitted from the dataset. Such "graveyard" funds are commonly the result of subpar investment performance. Through their omission from the data sample, an upward bias is present skewing the performance results. A second bias, as documented by Park (1995), is the "instant history" bias or incubation bias. Fung and Hsieh (2000) explain that newly originated hedge funds often operate on the basis of capital from close friends and family and don't publish performance results until a solid track record is developed. An incubation bias, excluding the initial underperformance, is therefore typically offered and marketed by database vendors. The exclusion of poor performance in a fund's early history will create an upward bias. Fung and Hsieh (2006) propose an upward draw of 1.8\% to $2.4 \%$ from the survivorship bias and roughly $1.5 \%$ from the incubation bias, per annum. We include defunct funds in our analyses and therefore avoid survivorship bias; however, there may be incubation bias present. This bias may be present within our results through reported alphas and factor loadings on model components.

\subsection{Creation of the Equity Financing Factor}

We create the equity financing factor (UMO) based on Hirshleifer and Jiang (2007), where UMO is long the equal-weighted portfolio of repurchase firms (U) and short the equal-weighted portfolio of new issue firms (O). Portfolios U (underpriced) and $\mathrm{O}$ (overpriced) are created at the end of June each year. Firms with repurchases in the two most recent fiscal years, with the most recent fiscal-year end as of the prior December, but without IPOs or SEOs in the past 24 months, are included in portfolio U. Firms with IPOs or SEOs in the past 24 months, ending in December, but without repurchases in the two most recent fiscal years, are included in portfolio O. Stock returns are equally weighted inside the $\mathrm{U}$ and $\mathrm{O}$ portfolios. The portfolios are held from July of year $\mathrm{t}$ to June of year $t+1$. There should be a positive coefficient on UMO if the factor is being successfully arbitraged.

\subsection{Creation of the Asset Growth Factor}

The asset growth factor (AGF) is created based on Cooper, Gulen, and Schill (2007), where the firm asset growth rate for calendar year $t$ is estimated in equation (3) as the percentage change in total assets from the fiscal year ending in calendar year $\mathrm{t}-2$ to the fiscal year ending in calendar year $\mathrm{t}-1$ :

$$
r_{A}=\frac{\left(\text { TotalAssets }_{t-1}-\text { TotalAsset }_{t-2}\right)}{\text { TotalAssets }_{t-2}}
$$

The asset growth rate is updated at the end of June of each year. At the end of June, stocks are sorted by $\mathrm{r}_{\mathrm{A}}$ and portfolio deciles are formed. Firms are equally weighted within the portfolios. AGF is created by going long the lowest $r_{A}$ decile and shorting the highest $r_{A}$ decile. Successful arbitraging of AGF will lead to a positive coefficient on the factor.

\subsection{Creation of the Earnings Momentum Factor}

We follow Chordia and Shivakumar (2006) to create the earnings momentum factor, PMN (Positive surprise earnings Minus Negative surprise earnings) Chordia and Shivakumar (2006) find a strong correlation between PMN and future stock returns and Lawson (2017) finds that PMN explains up to $3 \%$ of the returns of large funds with equity long only and equity short bias strategies. For the purposes of this study, we expect to see a positive loading on the PMN factor if fund managers are able to successfully arbitrage on the unexpected earnings announcements. 


\section{Results}

\subsection{Descriptive Statistics}

Descriptive statistics for the monthly excess returns are provided in Panel A of Table 1 and hedge fund strategies by utilization and performance are highlighted in Panel B. Table 1 Panel A and Panel B have been condensed for brevity. Over the period of January 1, 1994 to December 31, 2008, all monthly mean returns were positive, as expected. Interestingly, the equity short-bias, PIPEs, and fund timing strategies, being members of the top-five performers, were of the least-used strategies. The fixed income and emerging markets strategies were cited as top-used, but surprisingly ranked in the bottom-five performers.

Table 1. Panel A - descriptive statistics for monthly hedge fund returns by strategy

\begin{tabular}{lccccc}
\hline & NUMBER & MEAN NUMBER OF & \multicolumn{2}{c}{ VALUE-WEIGHTED MONTHLY RETURNS } \\
\cline { 4 - 6 } HEDGE FUND STRATEGY & OF FUNDS & MONTHLY RETURNS & MEAN & MEDIAN & SD \\
\hline TOTAL - ALL STRATEGIES & 3665 & 70 & 0.58 & 0.74 & 5.17 \\
\hline
\end{tabular}

Table 1. Panel B - hedge funds strategies by utilization and performance

\begin{tabular}{lccccc}
\hline & NUMBER & MEAN NUMBER OF & \multicolumn{2}{c}{ VALUE-WEIGHTED MONTHLY RETURNS } \\
\cline { 4 - 6 } HEDGE FUND STRATEGIES & OF FUNDS & MONTHLY RETURNS & MEAN & MEDIAN & SD \\
\hline w/ 50 OR MORE FUNDS & 3518 & 70 & 0.58 & 0.74 & 5.16 \\
\hline
\end{tabular}

Table 2 reports mean percentage returns for the Fama and French (1993) market, size, and value factors, the Carhart (1997) momentum factor, the four orthogonalized anomaly factors, and the Fung and Hsieh (2001) trend-following risk factors are provided. Table 2 has been omitted for brevity. The market, value, and size factors are all statistically insignificant, while the Carhart (1997) momentum factor is significant at the 5\% level. All three anomaly factors are significant at the $1 \%$ level. The return of the PTFS stock index lookback straddle (PTFSSTK) is significant at the $1 \%$ level while all other trend-following risk factors remain insignificant.

\subsection{Time Series Regression of All Hedge Funds}

Panel A of Table 3 reports the regression results for the net-of-fees, monthly, mean, value-weighted, excess returns generated by hedge fund strategies with 10 or more funds and 50 or more funds. Table 3 has been omitted for brevity. Regressing the four-factor model on excess returns from strategies with ten or more funds only, the market and momentum premiums were positive and significant at the $1 \%$ level. No significance was found on the traditional size and value premiums. The anomaly factors were significant when individually added to the four-factor model. Coefficients for AGF and PMN were positive and significant at the $1 \%$ level, while UMO was negative and significant at the 5\% level. The negative coefficient on the equity financing factor suggests that the average hedge fund implements, on some level, a strategy opposite of that described by Hirshleifer and Jiang (2007). That is, the average fund implements a strategy consistent with going short repurchase firms and long new issue firms.

Within the seven-factor model, the market and momentum factors, as well as AGF and PMN, held their positive and $1 \%$ significance. The positive loading on the asset growth factor supports the notion that the average hedge fund actively goes long firms shrinking their asset base and short firms expanding total assets. The AGF factor adds $0.068 \%$ per month to value-weighted excess returns and PMN contributes $0.143 \%$ per month. This AGF result corroborates the findings of Cooper, Gulen, and Schill (2007) such that an asset growth effect does seem to exist. The once again negative loading on the equity financing factor (UMO) is suggestive of a contrasting long-short strategy. Overall, the seven-factor alpha of $0.149 \%$ was significant. Based on the intercept, it can be suggested that the average hedge fund may be leveraging additional anomalies to generate return premium.

Using the excess returns from strategies with fifty or more funds, the five regressions were run once again. Very little had changed with respect to factors loadings, signs, and significance levels. UMO continued to exhibit an unexpected negative sign. As the equity financing factor was added to the model, the reported alpha increased to offset the effect generated by the negative factor loading. If funds could preserve their asset and security selection skills, only choosing assets which load positively on the anomaly factors, active returns would be more favorable. Overall, seven factor alpha generation was $0.145 \%$, which is both economically and statistically significant. As previously noted, such results suggest hedge funds are profiting from methods not captured within the model. 
Panel B of Table 3 reports four-factor regressions on strategies with ten or more funds, which reveals $1 \%$ statistical significance on PTFSBD, PTFSFX, PTFSCOM, and PTFSIR, where all coefficients are positive except on PTFSCOM. As the anomaly factors AGF, PMN, and UMO were individually added to the model only PMN and UMO had shown significance at the 5\% and $1 \%$ levels, respectively. Excess returns loaded positive on PMN while negative on UMO. The negative loading on UMO is contrary to expectations but in-line with our results from Panel A. Additionally, as the equity financing factor was added the significance on PTFSFX and PTFSSTK was lost.

The seven-factor model offered interesting results. All trend-following risk factors were significant at the $1 \%$ or 5\% levels, except for PTFSFX. Of the three anomaly factors, the asset growth and earnings momentum factors were positive and significant at the $1 \%$ level. The equity financing factor was negative and significant at $1 \%$. Alpha was positive and significant contributing $0.699 \%$ to total excess returns.

Using the excess returns from strategies with fifty or more funds, the five regressions were run once again. Very little changed with respect to factors loadings, signs, and significance levels.

\subsection{Top 5 and Bottom 5 Performing Strategies with 10 or More Funds}

Table 4 reports regression results using excess returns of the top five performing and bottom five performing hedge fund strategies as the dependent variable. Table 4 has been omitted for brevity. The general four-factor model shows a positive loading and 1\% significance on both the market and momentum factors. Of the three anomaly factors, which were separately added to the model, only the equity financing factor held significance. That is, UMO was negative and significant at the 5\% level. The negative loading on UMO is indicative of the average hedge fund executing a strategy consistent with going short repurchase firms and long new issue firms. This is consistent with our findings from previous models but contrasting to existing literature.

Regressing all seven factors on the excess returns of the top five performing strategies the momentum, asset growth, and earnings momentum factors were all significant at the $1 \%$ level. Again, UMO was found to be negative. The market factor was also significant at the 5\% level and held a positive loading. Overall, seven-factor alpha generation was $0.578 \%$ per month.

Turning attention to the output generated using the bottom five performing strategies, a different set of outcomes were found. The traditional size factor carried a negative loading, contrary to expectation and previous findings. The negative loading on SMB suggests that funds go long large-capitalization firms and short small-capitalization firms. This is contrary to the findings of Fama and French (1993) which found outperformance using a small-cap emphasis.

Panel B of Table 4 details similar regression results using the trend-following risk factors instead of the traditional Fama-French (1993) and Carhart (1997) factors. Of the top five performing strategies with ten or more funds, PTFSCOM and PTFSSTK loaded positively on excess returns at the $1 \%$ level. The interest rate lookback straddle was also significant at the $1 \%$ level but carried a negative coefficient. The equity financing anomaly factor was negative and significant at the $1 \%$ level, while all other anomaly factors remained insignificant. Results from the seven-factor model had shown $1 \%$ significance on the PTFSCOM, PTFSIR, PTFSSTK, and UMO factors, and 5\% significance on the asset growth factor. PTFSIR and UMO held their negative loading.

Regressing on the bottom five performing strategies with ten or more funds, PTFSBD and PTFSFX carried negative and $1 \%$ significance in both the four-factor model, as well as during the inclusion of each individual anomaly factor. Statistical significance of $1 \%$ was found on the PTFSCOM, PTFSIR, and PTFSSTK variables. PTFSSTK, the stock index lookback straddle, carried a negative loading, and therefore underwent a sign reversion relative to its coefficients in the model for the top five performing strategies with ten or more funds. This suggests that the worst performing funds on average went [insert what this strategy means]... The seven-factor results showed consistent conclusions with the exception of minor losses in significance for PTFSCOM and PTFSSTK, both of which were still significant at the 5\% level. Seven-factor alpha generation was $0.570 \%$ per month, showing both statistical and economic significance.

\subsection{Top 5 and Bottom 5 Performing Strategies with 50 or More Funds}

Table 5 reports regression results using the top and bottom five performing strategies with fifty or more funds utilizing them. Table 5 has been omitted for brevity. Panel A begins by outlining the models which used the traditional Fama and Fench (1993) and Carhart (1997) factors. The regression results from the top five performing strategies estimated the market and momentum factors having positive and $1 \%$ significance, while the size and value factors remained insignificant. Turning to the seven-factor model, the market and momentum 
factors held that significance while the AGF and PMN factors loaded positively at the $1 \%$ level. The equity financing factor was not significant but did carry the negative sensitivity that was present throughout the prior empirical results.

As outlined in the four-factor results from the bottom five performing strategies, all Fama-French-Carhart factors were significant. The market factor was positive and significant at the $1 \%$ level. SMB loaded negative and HML loaded positive on the excess returns, both being significant at the 5\% level. Alpha generation was not significantly different from zero. The loading and significance on the market factor carried over through the seven-factor regression, while the size factor lost 5\% significance and all other Fama-French-Carhart factors turned insignificant. Of the three anomaly factors, the asset growth and earnings momentum factors both carried a positive loading and $1 \%$ significance. Seven-factor alpha generation was statistically insignificant.

Panel B of Table 5 outlines results swapping out the Fama-French-Carhart factors for the Fung and Hsieh (2001) factors. The risk factors were regressed on the excess returns from the top five performing strategies used by fifty of more funds, and the bottom five strategies used by fifty or more funds. Considering the four-factor results for the top five strategies, negative factor sensitivities were found on the PTFSBD and PTFSIR variables, while PTFSCOM carried positive. All three were significant at the $1 \%$ level. The return on the currency lookback straddle and the stock index lookback straddle were not significant at reasonable levels. Results of the seven-factor model had shown similar figures for the PTFSBD, PTFSIR, and PTFSCOM variables. All three anomaly factors were significant at the $1 \%$ level. AGF and PMN had positive beta factors, while UMO was negative. Seven factor alpha generation was $0.855 \%$ per month and was highly significant.

The four-factor regression results for the bottom five strategies had shown strong significance on all five trend-following risk factors. PTFSBD, PTFSFX, PTFSIR, and PTFSSTK carried negative beta coefficients. Similar results were generated using the seven-factor model, however, UMO was the only significant anomaly factor at the $1 \%$ level. Alpha generation was positive and both economically and statistically significant.

\section{Conclusions}

Results presented show consistent explanation of variance in excess returns by the traditional market risk premium. This held across all reported regressions. The Fama and French (1993) size and value factors did not significantly explain monthly mean excess returns generated by the hedge fund sample, with the particular exception of the bottom five performing strategies. Funds using the bottom five performing strategies were in fact leveraging known size and value factors to generate abnormal returns, albeit their low relative performance.

The three anomaly factors performed relatively well throughout all multi-factor models. The asset growth factor was utilized moderately and the earnings momentum factor was recurring among hedge funds across commonly used strategies. The equity financing factor was also frequently implemented by funds, however, in the opposite manner to which prior literature suggests profitable. Hirshleifer and Jiang (2007) and others find success in going long a portfolio of repurchase firms and short a portfolio of new issue firms. Our findings suggest that the average hedge fund implements a strategy opposite to that by going short repurchase firms and long new issue firms. Such funds would likely generate stronger performance if they were to act otherwise.

Overall, we find that the average hedge fund does not robustly leverage all known market anomalies. However, some hedge funds do seem to take advantage of the asset growth and earnings momentum factors. Further, the production of significant long-term alpha leads us to the conclusion that funds must be executing arbitrage or utilizing additional undocumented methods to generate excess return. We suggest further research into the hedge fund literature by considering alternative sources of hedge fund performance data.

\section{References}

Agarwal, V., \& Naik, N. (2004). Risks and portfolio decisions involving hedge funds. Review of Financial Studies, 17, 63-98. https://doi.org/10.1093/rfs/hhg044

Bachelier, L. (1900). Théorie de la spéculation. Gauthier-Villars. https://doi.org/10.24033/asens.476

Ball, R., \& Brown, R. (1968). An empirical evaluation of accounting numbers. Journal of Accounting Research, 6 , 159-178. https://doi.org/10.2307/2490232

Bernard, V., \& Thomas, J. (1989). Post-earnings announcement drift: delayed price response or risk premium. Journal of Accounting Research, 27, 1-35. https://doi.org/10.2307/2491062

Boehme, R., \& Sorescu, S. (2002). The long-run performance following dividend initiations and resumptions: Underreaction or product of chance? Journal of Finance, 57, 871-900. https://doi.org/10.1111/1540-6261.00445 
Booth, G., Kallunki, J., \& Martikainen, T. (1996). Post-announcement drift and income smoothing: Finnish evidence. Journal of Business, Finance and Accounting, 23, 1197-1211. https://doi.org/10.1111/j.1468-5957.1996.tb01165.x

Brav, A., Geczy, C., \& Gompers, P. A. (2000). Is the abnormal return following equity issuances anomalous?. Journal of Financial Economics, 56(2), 209-249. https://doi.org/10.1016/S0304-405X(00)00040-4

Brown, S., Goetzman, W., \& Ibbotson, R. (1999). Offshore hedge funds: Survival and performance 1989-1995. Journal of Business, 72, 91-118. https://doi.org/10.1086/209603

Brown, S., Goetzman, W., \& Park, J. (1997). Conditions for survival: Changing risk and the performance of hedge fund managers and CTAs. Working Paper, New York University Stern School of Business, Yale School of Management, and Long Island University.

Carhart, M. (1997). On persistence in mutual fund performance. Journal of Finance, 52, 57-82. https://doi.org/10.1111/j.1540-6261.1997.tb03808.x

Chordia, T., \& Shivakumar, L. (2006). Earnings momentum and price momentum. Journal of Financial Economics, 80, 627-656. https://doi.org/10.1016/j.jfineco.2005.05.005

Cooper, M., Gulen, H., \& Schill, M. (2007). Asset growth and the cross-section of stock returns. Journal of Finance, forthcoming. https://doi.org/10.2139/ssrn.760967

Daniel, K., \& Titman, S. (2006). Market reactions to tangible and intangible information. Journal of Finance, 61, 1605-1643. https://doi.org/10.1111/j.1540-6261.2006.00884.x

Eckbo, B. E., Masulis, R. W., \& Norli, Ø. (2000). Seasoned public offerings: Resolution of the "new issues puzzle'. Journal of Financial Economics, 56(2), 251-291. https://doi.org/10.1016/S0304-405X(00)00041-6

Fama, E., \& French, K. (1993). Common risk factors in the returns on stock and bonds. Journal of Financial Economics, 33, 3-56. https://doi.org/10.1016/0304-405X(93)90023-5

Fama, E., \& French, K. (2007). Dissecting anomalies. Working Paper, University of Chicago and Dartmouth College. https://doi.org/10.2139/ssrn.911960

Foster, G., Olsen, C., \& Shevlin, T. (1984). Earnings releases, anomalies and the behavior of security returns. Accounting Review, 574-603.

Fung, W., \& Hsieh, D. (1997). Empirical characteristics of dynamic trading strategies: The case of hedge funds. Review of Financial Studies, 10, 275-302. https://doi.org/10.1093/rfs/10.2.275

Fung, W., \& Hsieh, D. (2000). Performance characteristics of hedge funds and commodity funds: Natural vs. spurious biases. Journal of Financial and Quantitative Analysis, 35, 291-307. https://doi.org/10.2307/2676205

Fung, W., \& Hsieh, D. (2006). Hedge funds: An industry in its adolescence. Federal Reserve Bank of Atlanta Economic Review, 91, 1-34.

Fung, W., \& Hsieh, D. A. (2001). The risk in hedge fund strategies: Theory and evidence from trend followers. The Review of Financial Studies, 14(2), 313-341. https://doi.org/10.1093/rfs/14.2.313

Hew, D., Skerratt, L., Strong, N., \& Walker, M. (1996). Post-earnings announcement drift: Some preliminary evidence for the UK. Accounting and Business Research, 26, 283-293. https://doi.org/10.1080/00014788.1996.9729519

Hirshleifer, D., \& Jiang, D. (2007). Commonality in misvaluation, equity financing, and the cross section of stock returns.

Ikenberry, D., Lakonishok, J., \& Vermaelen, T. (1995). Market underreaction to open market share repurchases. Journal of Financial Economics, 39, 181-208. https://doi.org/10.1016/0304-405X(95)00826-Z

Keim, D. B., \& Ziemba, W. T. (Eds.). (2000). Security market imperfections in worldwide equity markets (Vol. 9). Cambridge University Press.

Kendall, M. G. (1953), The analysis of economic time-series-Part I: Prices. Journal of the Royal Statistical Society. Series A (General) 116(1), 11-25. https://doi.org/10.2307/2980947

Lakonishok, J., \& Vermaelen, T. (1990). Anomalous price behavior around repurchase tender offers. Journal of Finance, 45, 455-477. https://doi.org/10.1111/j.1540-6261.1990.tb03698.x

Lawson, D. (2017). Hedge Funds and Earnings Momentum. International Journal of Economics and Finance, 
9(10), 40-46. https://doi.org/10.5539/ijef.v9n10p40

Litner, J. (1965a). The Valuation of Risk Assets and the Selection of Risky Investments in Stock Portfolios and Capital Budgets. The Review of Economics and Statistics, 47, 13-37. https://doi.org/10.2307/1924119

Litner, J. (1965b). Securities Prices, Risk, and Maximal Gains from Diversification. The Journal of Finance, 20(4), 587-615.

Loughran, T., \& Ritter, J. (1995). The new issue puzzle. Journal of Finance, 50, 23-52. https://doi.org/10.1111/j.1540-6261.1995.tb05166.x

Loughran, T., \& Ritter, J. (2000). Uniformly least powerful tests of market efficiency. Journal of Financial Economics, 55, 361-389. https://doi.org/10.1016/S0304-405X(99)00054-9

Markowitz, H. (1952). Portfolio selection. The Journal of Finance, 7(1), 77-91.

Marquering, W., Nisser, J., \& Valla, T. (2006). Disappearing anomalies: a dynamic analysis of the persistence of anomalies. Applied Financial Economics, 16(4), 291-302. https://doi.org/10.1080/09603100500400361

Mitchell, M., \& Pulvino, T. (2001). Characteristics of risk and risk arbitrage. Journal of Finance, 56, $2135-2175$. https://doi.org/10.1111/0022-1082.00401

Mossin, J. (1966). Equilibrium in a capital asset market. Econometrica: Journal of the Econometric Society, 768-783. https://doi.org/10.2307/1910098

Park, J. (1995). Managed futures as an investment asset. Doctoral dissertation, Columbia University.

Sharpe, W. F. (1964). Capital asset prices: A theory of market equilibrium under conditions of risk. The Journal of Finance, 19(3), 425-442.

Treynor, J. L. (1961). Market value, time, and risk. Unpublished Manuscript. "Rough Draft" dated 8/8/61, \#95-2009. https://doi.org/10.2139/ssrn.2600356

Treynor, J. L. (1962). Toward a theory of market value of risky assets. Unpublished manuscript, 6, 831-868.

\section{Copyrights}

Copyright for this article is retained by the author(s), with first publication rights granted to the journal.

This is an open-access article distributed under the terms and conditions of the Creative Commons Attribution license (http://creativecommons.org/licenses/by/4.0/). 